\title{
Evaluation of Electrocardiography,
}

Echocardiography and Cardiac T2* for Cardiac Complications in Beta Thalassemia Major

\section{Fadime ERSOY DURSUN ( $\nabla$ drfadimeersoy@yahoo.com.tr)}

Goztepe Prof Dr Suleyman Yalcin City Hospital: Medeniyet Universitesi Goztepe Egitim ve Arastirma Hastanesi https://orcid.org/0000-0002-3577-188X

\section{Gonul Aciksari}

Goztepe Prof Dr Suleyman Yalcin City Hospital: Medeniyet Universitesi Goztepe Egitim ve Arastirma Hastanesi

\section{Sercin Ozkok}

Goztepe Prof Dr Suleyman Yalcin City Hospital: Medeniyet Universitesi Goztepe Egitim ve Arastirma Hastanesi

\section{Onur Incealtin}

Goztepe Prof Dr Suleyman Yalcin City Hospital: Medeniyet Universitesi Goztepe Egitim ve Arastirma Hastanesi

\section{Research Article}

Keywords: Thalassemia major, ferritin, cardiac T2*, electrocardiography, echocardiography

Posted Date: July 9th, 2021

DOI: https://doi.org/10.21203/rs.3.rs-657718/v1

License: (c) (1) This work is licensed under a Creative Commons Attribution 4.0 International License. Read Full License

Version of Record: A version of this preprint was published at The International Journal of Cardiovascular Imaging on October 8th, 2021. See the published version at https://doi.org/10.1007/s10554-021-02421-x. 


\section{Abstract}

Cardiac complications such as heart failure and arrhythmias caused by "iron-induced" cardiomyopathy are considered as the primary cause of death in the patients with $\beta$-thalassemia major. The aim of this study was to evaluate electrocardiography, echocardiography according cardiac $\mathrm{T} 2^{\star}$ and ferritin findings of patients followed-up for $\beta$-thalassemia major, and to investigate the importance of these findings for early detection of cardiac complications. The study included 41 patients and 25 healthy individuals with matched age and gender. The cardiac T2* results revealed a cardiac iron load below $20 \mathrm{msec}$ in 12 (29.27\%) patients, and above $20 \mathrm{msec}$ in 29 (70.73\%) patients. All electrocardiography parameters except JTc interval significantly increased in the patient group when compared to the control group $(p<0.05)$. All parameters except $P$ wave segment in electrocardiography and T peak-end/QT ratio were significantly higher in the group with cardiac T2* $<20 \mathrm{msec}$ than the group with cardiac T2* $>20 \mathrm{msec}(\mathrm{p}<0.05)$. Intraventricular septum thickness, left ventricular posterior wall thickness, left ventricular mass and left ventricular mass index detected by echocardiography were significantly higher in the group with $\mathrm{T} 2 *<20$ msec $(p<0.05)$. Electrocardiography, echocardiography, cardiac T2* and ferritin findings should be carefully evaluated in these patients in order to detect early signs of cardiac complications.

\section{Introduction}

Thalassemia syndromes are haemoglobin disorders characterized by decreased synthesis or failure to synthesize globin chains in the haemoglobin structure. If there is a disorder in the alpha chain production of haemoglobin, alpha-thalassemia appears; and if there is a production disorder in the beta chain, betathalassemia major appears ( $\beta$-TM). $\beta$-TM has a high prevalence in the Mediterranean, Middle East, Caucasus, Central Asia, Indian subcontinent and Far East [1, 2].

The course of the disease depends on whether the patient receives appropriate transfusion and iron chelation therapy. Life expectancy in patients who do not receive adequate transfusion and chelation therapy is less than 5 years. These patients usually die due to anaemia, heart failure, liver failure [3-5]. Cardiac complications such as heart failure and arrhythmias caused by "iron-induced" cardiomyopathy are considered as the primary cause of death in the patients with $\beta$-TM [5-7].

One of the symptoms of cardiac failure is prolongation of PR interval on electrocardiography (ECG) in patients with $\beta$-TM. Abnormalities of the T wave are a late finding. Rhythm disorders often start with atrial extra-systoles in the second decade. Ventricular extra-systoles may occur in the middle of the second decade and their frequency gradually increases. If there is a decrease in the ejection fraction (EF) on echocardiography $(\mathrm{ECHO})$ along with resistant arrhythmias, this finding is accepted as a sign that symptomatic cardiac failure will develop within one year [8-10]. Since biopsy is an invasive procedure to measure myocardial iron accumulation, alternative methods are needed. For this purpose, the cardiovascular T2* magnetic resonance imaging (MRI) which is a non-invasive method has become the gold standard to evaluate the cardiac response to iron chelation therapy in patients with $\beta$-TM in order to measure myocardial iron and determine ventricular functions $[11,12]$. The expected life period in more 
than half of the patients who develop cardiac failure after the failure is less than 3 months and one third progresses mortally [13]. Therefore, diagnosing at subclinic stage is very valuable. Therefore, it is very important to evaluate the cardiac status through ECG, ECHO, 24-hour ECG monitoring, radionuclide cinangiography after exercise, annual cardiac T2* MRI in all patients over the age of 10 at regular intervals [14-16].

The aim of this study was to evaluate the blood ferritin level, ECG, ECHO and T2* MRI findings in patients with adult $\beta-T M$, to evaluate the cardiac iron deposition findings, and to emphasize their importance in early detection of cardiac complications by examining the relationships between these parameters.

\section{Materials And Methods}

\section{Patient Populations}

This retrospective study was performed in Haematology Department of Istanbul Prof. Dr.Süleyman Yalçın City Hospital between March 2021 and June 2021. A total of 41 patients including 25 females and 16 males diagnosed with $\beta$-TM between the age of 18 and 55 years were included in the study. A total 25 healthy subjects including 16 females and 9 males matched with the patients for age and gender were included in the control group. The cases taken for control were randomly selected from male and female who applied to the Cardiology outpatient clinic for routine control and did not have any cardiac pathology. The study was approved by the local ethics committee of Medeniyet University Faculty of Medicine prior onset of the study (no:2021/0257). However, written informed consent for the study was obtained from each participant after a data-oriented explanation was made about the aims and scope of the study in accordance with the principles of the World Medical Association Declaration of Helsinki.

All patients received regular erythrocyte suspension transfusion every 3 weeks in average and continuous oral iron chelation therapy (deferoxamine or deferiprone or combination therapy with both agents). Patients with any other chronic disease, systolic heart failure, chronic atrial fibrillation, end-stage renal failure, liver failure, electrolyte disorder, any acute or recurrent infection, any malignancy, thyroid disease, those using anti-arrhythmic drugs, drugs that prolong the QT interval, patients with a chronic inflammatory condition, those who have not accepted to participate into the study, and patients who do not receive a chelation treatment regularly were excluded.

\section{The Study Protocol}

Demographic findings, systemic examinations, cardiologic examinations, Cardiac T2* MRI, ECG, ECHO, complete blood count, biochemical analyses and ferritin level analysis results obtained during routine controls were recorded retrospectively from patient files and hospital automation system of Thalassemia Centre within Prof. Dr. Süleyman Yalçın City Hospital. Considering the patients receiving blood transfusion every 3 weeks, it was accepted that an average of 17 transfusions were made per year.

\section{Cardiac T2* Magnetic Resonance Imaging}


The cardiac iron load was evaluated by cardiac T2* MRI. For this purpose, ECG triggered MRI's were obtained through 1.5 tesla (T) magnet GE 450W (Signa HDx; GE Medical Systems, Milwaukee, WI, USA) device and 32 channel abdominal coil. Total exam period was approximately 10 minutes for each patient. The multi-TE GRE sequence at different echo times of breath holding (TE 3, 7, 10, 14, 17, 20, 23, 26 and $29 \mathrm{msec}$ ) was used to detect cardiac iron accumulation. T2* MRI sequenced parameters were determined repetition time $=500 \mathrm{msec}, \mathrm{FA}=20$, slice thickness $=6 \mathrm{~mm}$, matrix $=128 \times 256, \mathrm{FOV}=350 \mathrm{~mm}, 7$ phased coding stage for each cardiac cycle and 15 to $25 \mathrm{sec}$ acquisition time. The signal value from interventricular septum was measured with region of interest (ROI) $1-1.5 \mathrm{~cm}^{2}$ at single midventricular short axis images. If T2* $>20 \mathrm{msec}$, it was normal, values $<20 \mathrm{msec}$ was accepted as increased cardiac iron load [17].

\section{Electrocardiography}

Standard 12-lead ECGs with $10 \mathrm{~mm} / \mathrm{mV}$ amplitude at a speed of $25 \mathrm{~mm} / \mathrm{sec}$ at rest for each patient were recorded with a Nihon Kohden Cardiofax M 1350 K ECG device. The vertical axis on ECG was $1 \mathrm{mV}=10$ $\mathrm{mm}$ and the horizontal axis was $25 \mathrm{~mm} / \mathrm{sec}$ standard rate. The $\mathrm{P}$ wave, $\mathrm{P}$ wave dispersion, PR segment, QRS complex, QT, QT dispersion, QTc, QTc dispersion, JT, JTc, JTc dispersion, T wave, T peak-end, T peakend dispersion and T peak-end/QT ratio was calculated by a Cardiologist who was blind to the patients and the patient data. An average value was calculated from 3 readings for each derivation. The QT dispersion was calculated as the difference between maximum QT interval and the minimum QT interval in any derivation. The QT interval was calculated as corrected QT (QTc) through Bazzet's formula (QTC = QT/ $\sqrt{ }$ R-R interval). ${ }^{18}$ The QTc dispersion (QTcd) was calculated as the difference between maximum QTC interval and the minimum QTc interval in any derivation. The JT interval was obtained by subtracting the QRS from the QT interval. The JT dispersion was obtained by subtracting the minimum JT from maximal JT. The JTc was calculated through Bazzet's formula (JTc $=J T / \sqrt{ } R-R$ interval) [18]. T peak-end interval is the time from the peak of the $T$ wave to the end of the $T$ wave. The T peak-end measurements were calculated from the data obtained from precordial leads. The T peak-end/QT ratio was calculated by these data.

\section{Echocardiography}

The same cardiologist who has assessed ECG measurements evaluated all patients with ECHO. The Mmode, two dimensional and Doppler ECHO studies were performed by using Philips EPIQ 7 (Philips Healthcare, Inc., Andover, MA) ECHO device and 2.5 and $3.5 \mathrm{mHz}$ transducer. Conventional ECHO measurements were performed according to the standards of American Association of Echocardiography [19]. ECG and phonocardiogram records were taken simultaneously during the echocardiographic examination; all measurements were made in at least 3 cardiac cycles separately, and their mean values were calculated. Left ventricular end-diastolic diameter (LVEDD), left ventricular end systolic diameter (LVESD), interventricular septum thickness (IVST), left ventricular posterior wall thickness (LVPWT), left ventricular mass (LVM) and left ventricular mass index (LVMI) were measured through M-mode 
echocardiographic examination. Furthermore, the ejection fraction (EF) and Fractional Shortening (FS) were recorded by calculating from the tool.

\section{Statistical analysis}

The statistical analysis was performed using SPSS software (version 25.0; SPSS Inc., Chicago, IL, USA). If the distribution of the continuous variables was normal, they were presented as mean $\pm S D(p>0.05$ on the Kolmogorov-Smirnov or Shapiro-Wilk test; $n<30$ ). If the continuous variables were not normally distributed, they were described as the median (min-max). Intergroup comparisons were analysed using Student's t-test or one-way analysis of variance for normally distributed data, while the Mann-Whitney $U$ test or Kruskal-Wallis test were used to examine non-normally distributed data. Correlations between variables were tested by Spearman correlation coefficient. P-values $<0.05$ were considered statistically significant.

\section{Results}

Forty patients enrolled into the study included $25(60.98 \%)$ females and $16(39.02 \%)$ males with an age average of $28.5 \pm 7.8(18-55)$ years. The control group consisted of 25 individuals including $16(64 \%)$ females and $9(36 \%)$ males with an age average of $30.10 \pm 10.48(18-54)$ years. There was not any statistically significant difference between the patient and control groups for age and gender $(p=0.434$ and $p=0.806$, respectively). Demographic and clinical features of the patients and control group enrolled were presented in Table 1. Although the patients were similar for age and gender, weight, height and body mass index (BMI) were lower in the patient group than the control group $(p=0.001, p=0001$ and $p=$ 0.027, respectively). Hemoglobin level was lower in the patient group than the control group; however, platelet count, white blood cells (WBC) count, uric acid level, total bilirubin level and ferritin levels were higher than the control group $(p=0.001, p=0.001, p=0.021, p=0.017, p=0.001$ and $p=0.008$, respectively).

Cardiac T2* MRI findings and total count of blood transfusions were presented in Table 2. Since the patients received blood transfusion every 3 weeks, it was accepted that an average of 17 transfusions were performed per year. This indicates that patients totally received $479.40 \pm 133.81$ units of blood in average. The review on T2* results obtained by MRI for the heart revealed that $12(29.27 \%)$ patients had higher cardiac iron load with a cardiac T2*<20 msec (Fig. 1A); however, 29 (70.73\%) patients had normal cardiac iron load with a cardiac T2* 20 msec (Fig. 1B). Plasma ferritin level of 12 (29.27\%) patients with cardiac T2* MRI result $<20 \mathrm{msec}$ was above $3.000 \mathrm{ng} / \mathrm{mL}$.

ECG and ECHO findings of the patient and control groups were provided in Table 3. We detected the heart rate, $\mathrm{P}$ wave, $\mathrm{P}$ wave dispersion, PR segment, QRS segment, QT, QT dispersion, QTc, QTc dispersion, JT, JTc dispersion, T peak-end, T peak-end dispersion and T peak-end/QT ratios significantly higher in the patient group when compared to the control group ( $p<0.05$, Fig. 2A, 2B, 2C). However, JTc periods were found within normal limits $(p=0.446)$. When the cardiac ECHO findings of the patients were examined, $E F$ was $<55 \%$ in 1 patient only; EF results of the other patients were normal. The IVST was $>100 \mathrm{~mm}$ and 
thicker than normal in 2 patients; however, it was normal in other patients. Shortening fraction (FS), LVPWT was within normal limits in all patients. Similarly, LVEDD and LVESD were found within normal limits in all patients. Comparison of these ECHO parameters with the control group revealed no statistically significant difference $(p=n s)$. On the other hand, LVM and LVMI were increased in the patients compared to the controls, and there was a statistically significant difference between the two groups ( $p=0.004$ and $p=0.009$ respectively, Fig. 3 ).

The patients were divided into 2 groups as cardiac T2* $<20 \mathrm{msec}$ and T2* $>20 \mathrm{msec}$ (Table 4). We detected the heart rate, P wave, P wave dispersion, PR segment, QRS segment, QT, QT dispersion, QTc, QTc dispersion, JT, JTc dispersion, T peak-end, T peak-end dispersion and T peak-end / QT ratios significantly higher in the cardiac $\mathrm{T} 2^{*}<20 \mathrm{msec}$ group when compared to the cardiac $\mathrm{T} 2 *>20 \mathrm{msec}$ group $(p)$.

When the patients were divided into 2 groups as $\mathrm{T} 2^{\star} \mathrm{MRI}<20 \mathrm{msec}$ and $>20 \mathrm{msec}$, review of cardiac ECHO findings revealed no statistically significant difference between the two groups in terms of EF, FS, LVEDD and LVESD ( $p=n s$; table 4). However, IVST, LVPWT, LVM and LVMI values were significantly higher in the T2*MRI $<20$ msec group $(p=0.001, p=0.030, p=0.001$ and $p=0.001$, respectively).

The association between ECG and ECHO findings and cardiac T2 * and ferritin levels were examined in the patient group (table 5). A negative correlation was found between heart rate and PR interval, and cardiac T2* MRI values $(r=-0.577, p=0.001$ and $r=-0.565$, and $p=0.001$, respectively). Similarly there was a negative correlation was found between LVM and LVMI and cardiac T2* scores $(r=-0.407, p=0.008$ and $r=-0.368, p=0.018$, respectively). On the other hand, there was not any association between other ECG and ECHO findings and cardiac T2*. A positive correlation was found between the QRS interval and ferritin in consideration of the association between ECG and ECHO findings and ferritin in the patient group, $(r=0.315, p=0.048)$. There was not any association between other ECG and ECHO findings and ferritin.

\section{Discussion}

The associations of ECG, ECHO, T2* MRI and ferritin levels with results of these exams were evaluated in patients with $\beta$-TM. Cardiac T2* MRI results were within pathological limits (<20 msec) in $12(29.27 \%)$ patients. All parameters (except JTc interval) in ECG were detected significantly increased in patients with $\beta$-TM when compared to the control group of this study. On the other hand, LVM and LVMI were increased in the patient group compared to the control group, and a statistically significant difference was found between the two groups. However, there was not any statistically significant difference in other ECHO findings. When the patients were examined by dividing them into 2 groups according to cardiac $T 2 *$ score results as $<20 \mathrm{msec}$ and $>20 \mathrm{msec}$, all findings in except $\mathrm{P}$ wave and T peak-end/QT were detected increased in the T2* scores $<20 \mathrm{msec}$ group when compared to T2* $>20 \mathrm{msec}$ group. In ECHO findings, IVST, LVPWT, LVM and LVMI were increased in T2* $<20 \mathrm{msec}$ group; there was not any difference for other parameters. When the correlation between cardiac T2* and ECG and ECHO findings was reviewed, a 
negative correlation was found between the heart rate, PR interval, LVM and LVMI and cardiac T2*. On the other hand, a positive correlation was detected between ferritin and QRS interval.

The height, weight and BMI values of patients were lower than the control group in our study. Furthermore, lower haemoglobin level and higher platelet count, WBC count, uric acid level, total bilirubin level and ferritin levels in the patients are considered to develop due to frequent transfusions, and this is a common finding (table 1). Although it is less common in patients receiving regular transfusions, retardation of growth is an expected finding in patients with $\beta$-TM. Anemia is not the only cause of growth retardation in these patients. Not using a regular chelator is also one of the factors that cause impairment in growth hormone production. Furthermore, chelators themselves may cause growth retardation. Along with aging, the retardation of growth and development, prominence on the bones of the maxillary region, protrusion on the frontal bones, and a specific facial appearance defined as "thalassemia face" appears [20, 21].

We detected cardiac T2* MRI result of $12(29.27 \%)$ of 41 patients as $<20 \mathrm{msec}$. The presence of iron overload in 12 patients despite receiving iron chelation therapy regularly is an indicator of how susceptible patients with $\beta$-TM are to cardiac complications (table 2 ). Cardiac iron accumulation is generally increased in patients with $\beta$-TM due to frequent transfusions despite chelation therapy, and T2* MRI is used to show cardiac iron load $[11,12,22,23]$. Therefore, T2* MRI is performed once a year regularly as in our patients. Since biopsy is an invasive procedure to measure myocardial iron accumulation, alternative methods are needed. For this purpose, the cardiovascular T2* MRI which is a non-invasive method has become the gold standard to evaluate the cardiac response to iron chelation therapy in patients with $\beta$-TM in order to measure myocardial iron and determine ventricular functions $[11,12,24,25]$.

Cardiac complications caused by excessive iron overload are pericarditis, arrhythmias, and myocardial dysfunction. We had our patients to have ECG at every control in order to detect cardiac rhythm disorders of our patients earlier. As shown in Table 3, all ECG parameters except JTc interval were found significantly prolonged in the patients when compared to the controls. One of the symptoms of cardiac failure is prolongation of PR interval on ECG. Abnormalities of the T wave are a late finding. It is more common in those at older age and higher iron load [26]. Rhythm disorders often start with atrial extrasystoles in the second decade. Ventricular extra-systoles may occur in the middle of the second decade and their frequency gradually increases [27]. If there is a decrease in the ejection fraction (EF) along with resistant arrhythmias, this finding is accepted as a sign that symptomatic cardiac failure will develop within one year. Atrial and ventricular pulses, paroxysmal atrial tachycardia, flutter, and fibrillation may be observed as a result of iron accumulation in the cardiac conduction systems $[28,29]$. The conduction system and atria are affected less than ventricles. Patients with mild cardiac dysfunction are usually limited with perinuclear areas, and a few fibre cells are affected. It is observed that a large number of myocardial fibre cells are affected by iron deposition in patients with obvious cardiac dysfunction [26]. 
Our patients who are followed up in our centre are evaluated with $\mathrm{ECHO}$ once a year in order to detect other cardiac complications and cardiac functions, except rhythm disorders, if any. For this purpose, we evaluated EF, FS, LVEDD, LVESD, IVST and LVPWT by ECHO. LVM and LVMI were significantly higher in patients when compared to the controls. We did not find any statistically significant difference in other ECHO parameters in the patient and control groups. Although it was not statistically significant, IVST measurements were found increased in the patient group when compared to the control group. Iron accumulation in the heart causes hypertrophy, enlargement, and myocardial fibrosis. Heart failure due to iron accumulation in the myocardium often occurs around 20 years of age. The cardiac decompensation caused by iron load is the cause for $70 \%$ of deaths $[7,8,30]$. The iron is deposited in myocytes in the cardiac muscle. The free iron atom in the myocyte increases free radical production and causes deterioration in the structure of the mitochondrial respiratory chain [31].

Twelve of our patients with cardiac T2* result below $20 \mathrm{msec}$ were patients with higher cardiac iron load, and 29 patients were with cardiac T2* result above $20 \mathrm{msec}$ were those with normal cardiac iron load. When ECG findings were considered, all ECG findings except $P$ wave duration and T peak-end/QT ratio were found significantly prolonged in our patients with cardiac T2* results below $20 \mathrm{msec}$ when compared to patients with cardiac T2* results above $20 \mathrm{msec}$. These results indicate that those with increased cardiac iron load may have more arrhythmia problems. When evaluated according to these results, it is considered that the increase in ECG disorders in the patients may also be related with cardiac iron load when compared to the controls. Previous studies that evaluate the results obtained with cardiac T2* in patients with $\beta$-TM found that ECG findings of patients with increased cardiac iron load presented arrhythmic findings [32-34].

Cardiac T2 * results showed that IVST, LVPWT, LVM and LVMI values were higher in patients with results below $20 \mathrm{msec}$ in comparison to patients with cardiac T2* findings above $20 \mathrm{msec}$. This result shows that our patients with cardiac T2* value below 20 msec started to be affected along with ECHO findings. Although these results are stated in many studies in the literature, they were not emphasized sufficiently in studies conducted on adults [32, 33].

The associations between ECG and ECHO findings as well as cardiac T2* and ferritin results of the patients were examined. The negative correlation of heart rate and PR interval with cardiac T2* result and the positive correlation of QRS interval with ferritin support each other. In addition, a negative correlation was found between the values obtained with LVM and LVMI in ECHO and the cardiac T2 * score. These results indicate that both cardiac $\mathrm{T} 2^{*}$ and serum ferritin level are important to monitor the development of cardiac complications. There are studies in the literature indicating that ECG findings and cardiac functions are associated with ferritin level and cardiac T2* results. Eghbali et al. did not detect any association between cardiac T2* findings and serum ferritin levels; however, Yuksel et al. found a negative correlation $[35,36]$.

\section{Limitations}


Our study had some limitations. The first limitation is conduction of the study on a small group of patients. Furthermore, we could not perform a 24-hour ECG monitoring and effort ECG monitoring. Therefore, our study may be insufficient to detect the development of prospective arrhythmic events.

\section{Conclusion}

Our study showed that atrial depolarization and ventricular repolarization parameters may be affected in $\beta$-TM. We also showed that these parameters were more pronounced in patients with higher cardiac iron load. The increase in IVST, LVPWT, LVM and LVMI of ECHO was shown to be increased in line with the cardiac iron load increase beyond ECG. Therefore, we showed that the ferritin, ECG, ECHO, and cardiac T2* MRI findings of patients with $\beta$-TM should be carefully evaluated. Furthermore, if further electrophysiological studies in addition to analyses of ferritin, ECG, ECHO, and cardiac T2* MRI with larger patient series are performed, definite results may be obtained about the prognosis of the patients for cardiac findings.

\section{Declarations}

Funding Our study has not received any financial support

Conflicts of interest/ Competing interests The authors have no conflicts of interest to declare.

Availability of data and material Not applicable

Code availability Not applicable

Authors' contributions Fadime Ersoy Dursun design to the study, collected patients data and wrote the article, Gönül Sarı design to the study and made and evalueted electrocardiography and echocardiography. Serçin Özkök evaluated T2* MRI. Onur Incealtin design to the study and evaluated the laboratory findings.

Ethics approval This study was approved by the local ethics committee of Medeniyet University Faculty of Medicine prior onset of the study(no:2021/0257).

Consent to participate Written informed consent for the study was obtained from each participant after a data-oriented explanation was made about the aims and scope of the study in accordance with the principles of the World Medical Association Declaration of Helsinki.

Consent for publication Not applicable

Acknowledgments We thank Ms Çağla Sarıtürk (statistician) who made the statistics of this study.

\section{References}


1. Cao A, Galanello R (2010) Beta-thalassemia. Genet Med 12: 61-76. https://doi.org/10.1097/ GIM.0b013e3181cd68ed

2. Origa R (2017) $\beta$-Thalassemia. Genet Med 19:609-619. https://doi.org/10.1038/gim.2016.173

3. Borgna-Pignatti C, Rugolotto S, De Stefano P et al (2004) Survival and complications in patients with thalassemia major treated with transfusion and deferoxamine. Haematologica 89:1187-1193

4. Olivieri NF, Nathan DG, MacMillan JH, Wayne AS, Liu PP, McGee A et al (1994) Survival in medically treated patients with homozygous beta-thalassemia. N Engl J Med 331: 574-578. https://doi.org/ 10.1056/NEJM199409013310903

5. Kremastinos DT, Farmakis D, Aessopos A, Hahalis G, Hamodraka E, Tsiapras D et al (2010) Betathalassemia cardiomyopathy: history, present considerations, and future perspectives. Circ Heart Fail 3: 451-458. https://doi.org/ 10.1161/CIRCHEARTFAILURE.109.913863

6. Walker JM (2013) Thalassaemia major and the heart: a toxic cardiomyopathy tamed? Heart 99:827834. https://doi.org/10.1136/heartjnl-2012-302857

7. Yang G, Liu R, Peng P, Long L, Zhang X, Yang W et al (2014) How early can myocardial iron overload occur in beta thalassemia major? PLoS One 9:e85379. https://doi.org/10.1371/journal.pone.0085379

8. Cogliandro T, Derchi G, Mancuso L, Mayer MC, Pannone B, Pepe A et al (2008) Society for the Study of Thalassemia and Hemoglobinopathies (SOSTE). Guideline recommendations for heart complications in thalassemia major. J Cardiovasc Med (Hagerstown) 9:515-525. https://doi.org/10.2459/JCM.0b013e3282f20847

9. Aessopos A, Berdoukas V, Tsironi M (2008) The heart in transfusion dependent homozygous thalassaemia today-prediction, prevention and management. Eur J Haematol 80:93-106. https://doi.org/10.1111/j.1600-0609.2007.01018.x

10. Berdoukas V, Chouliaras G, Moraitis P, Zannikos K, Berdoussi E, Ladis V (2009) The efficacy of iron chelator regimes in reducing cardiac and hepatic iron in patients with thalassemia major: a clinical observational study. J Cardiovasc Magn Reson 11:20. https://doi.org/10.1186/1532-429X-11-20

11. Anderson LJ, Holden S, Davis B, Prescott E, Charrier CC, Bunce NH et al (2001) Cardiovascular T2star $\left(\mathrm{T} 2^{\star}\right)$ magnetic resonance for the early diagnosis of myocardial iron overload. Eur Heart $\mathrm{J}$ 22:2171-2179. https://doi.org/10.1053/euhj.2001.2822

12. Borgna-Pignatti C, Meloni A, Guerrini G, Gulino L, Filosa A, Ruffo GB et al (2014) Myocardial iron overload in thalassaemia major. How early to check? Br J Haematol 164:579-585. https://doi.org/10.1111/bjh.12643

13. Pepe A, Meloni A, Rossi G, Caruso V, Cuccia L, Spasiano A et al (2013) Cardiac complications and diabetes in thalassaemia major: a large historical multicenter study. $\mathrm{Br} \mathrm{J}$ Haematol 163:520-527. https://doi.org/10.1111/bjh.12557

14. Li D, Dhawale P, Rubin PJ, Haacke EM, Gropler RJ (1996) Myocardial signal response to dipyridamole and dobutamine: demonstration of the BOLD effect using a double-echogradient-echosequence. Magn Reson Med 36:16-20. https://doi.org/10.1002/mrm.1910360105 
15. Origa R, Danjou F, Cossa S, Matta G, Bina P, Dessì C (2013) Impact of heart magnetic resonance imaging on chelation choices, compliance with treatment and risk of heart disease in patients with thalassemia major. Br J Haematol 163:400-403. https://doi.org/10.1111/bjh.12517

16. Kremastinos DT, Tsetsos GA, Tsiapras DP, Karavolias GK, Ladis VA, Kattamis CA (2001) Heart failure in beta thalassemia: a 5-year follow-upstudy. Am J Med 111:349-354. https://doi.org/10.1016/s0002-9343(01)00879-8

17. Anderson LJ (2011) Assessement of iron overload with T2* magnetic resonance imaging. Prog Cardiovasc Dis 54:287-294. https://doi.org/10.1016/j.pcad.2011.07.004

18. Bazett HC (1920) An analysis of the time-relations of electrocardiograms. Heart 7: 353-370. https://doi.org/

19. Lang RM, Badano LP, Mor-Avi V, Afilalo J, Armstrong A, Ernande L et al (2015) Recommendations for cardiac chamber quantification by echocardiography in adults: an update from the American Society of Echocardiography and the European Association of Cardiovascular Imaging. J Am Soc Echocardiogr 28:1-39.e14. https://doi.org/10.1016/j.echo.2014.10.003

20. Skordis N, Kyriakou A (2011) The multifactorial origin of growth failure in thalassaemia. Pediatr Endocrinol Rev 8:271-277

21. Low LC (1997) Growth, puberty and endocrine function in beta-thalassaemia major. J Pediatr Endocrinol Metab 10:175-184. https://doi.org/10.1515/jpem.1997.10.2.175

22. Koohi F, Kazemi T, Miri-Moghaddam E (2019) Cardiac complications and iron overload in beta thalassemia major patients-a systematic review and meta-analysis. Ann Hematol 98:1323-1331. https://doi.org/10.1007/s00277-019-03618-w

23. El-Shanshory M, Tolba O, El-Shafiey R, Elgamasy M, Hablas N, Mawlana W (2020) Cardiac Iron Overload by MRI in Children With B-Thalassemia Major and its Correlation With Cardiac Function by Echocardiography. Pediatr Hematol Oncol 42:398-402. https://doi.org/10.1097/MPH.0000000000001786

24. Kondur AK, Li T, Vaitkevicius P, Afonso L (2009) Quantification of myocardial iron overload by cardiovascular magnetic resonance imaging $\mathrm{T} 2{ }^{*}$ and review of the literature. Clin Cardiol 32:E55E59. https://doi.org/10.1002/clc.20310

25. Kobayashi M, Suhara T, Baba Y, Kawasaki NK, Higa JK, Matsui T (2018) Pathological Roles of Iron in Cardiovascular Disease. Curr Drug Targets 19: 1068-1076. https://doi.org/ $10.2174 / 1389450119666180605112235$

26. Detterich J, Noetzli L, Dorey F, Bar-Cohen Y, Harmatz P, Coates T et al (2012) Electrocardiographic consequences of cardiac iron overload in thalassemia major. Am J Hematol 87:139-144. https://doi.org/10.1002/ajh.22205

27. Hamed AA, Elguindy W, Elhenawy YI, Ibrahim RH (2016) Early Cardiac Involvement and Risk Factors for the Development of Arrhythmia in Patients With beta-Thalassemia Major. J Pediatr Hematol Oncol 38:5-11. https://doi.org/10.1097/MPH.0000000000000467 
28. Chrysohoou C, Panagiotakos DB, Barbetseas Y, Brilli S, Lambrou S, Karagiorga M et al (2004) Echocardiographic and electrocardiographic prognostic factors of heart failure in young patients with beta-thalassemia major: a 10-year (1995-2004) follow-up. Int J Hematol 80:336-340. https://doi.org/10.1532/ijh97.e0407

29. Bayar N, Kurtoğlu E, Arslan Ş, Erkal Z, Çay S, Çağırcı G et al (2015) Assessment of the relationship between fragmented QRS and cardiac iron overload in patients with beta-thalassemia major. Anatol J Cardiol 15:132-136. https://doi.org/10.5152/akd.2014.5188

30. Rodrigues A, Guimarães-Filho FV, Braga JC, Rodrigues CS, Waib P, Fabron-Junior A et al (2013) Echocardiography in thalassemic patients on blood transfusions and chelation without heart failure. Arq Bras Cardiol 100:75-81. https://doi.org/10.1590/s0066-782x2013005000001

31. Mancuso L, Vitrano A, Mancuso A, Sacco M, Ledda A, Maggio A (2018) Left Ventricular Diastolic Dysfunction in beta-Thalassemia Major with Heart Failure. Hemoglobin 42: 68-71. https://doi.org/ 10.1080/03630269.2018.1451341

32. Barzin M, Kowsarian M, Akhlaghpoor S, Jalalian R, Taremi M (2012) Correlation of cardiac MRI T2* with echocardiography in thalassemia major. Eur Rev Med Pharmacol Sci 16:254-260

33. Garadah TS, Kassab S, Mahdi N, Abu-Taleb A, Jamsheer A (2010) QTc Interval and QT Dispersion in Patients with Thalassemia Major: Electrocardiographic (EKG) and Echocardiographic Evaluation. Clin Med Insights Cardiol 4:31-37. https://doi.org/10.4137/cmc.s4472

34. Magrì D, Sciomer S, Fedele F, Gualdi G, Casciani E, Pugliese P et al (2007) Increased QT variability in young asymptomatic patients with beta-thalassemia major. Eur J Haematol 79:322-329. https://doi.org/10.1111/j.1600-0609.2007.00921.x

35. Yuksel IO, Koklu E, Kurtoglu E, Arslan S, Cagirci G, Karakus V et al (2016) The Association between Serum Ferritin Level, Tissue Doppler Echocardiography, Cardiac. T2* MRI, and Heart Rate Recovery in Patients with Beta Thalassemia Major. Acta Cardiol Sin 32:231-238. https://doi.org/10.6515/acs20150824a

36. Demircan T, Onder Sivis Z, Tatlı Güneş B, Karadeniz C (2020) Evaluation of electrocardiographic markers of cardiac arrhythmic events and their correlation with cardiac iron overload in patients with beta-thalassemia major. Cardiol Young 30:1666-1671. https://doi.org/10.1017/S1047951120002498

\section{Tables}


Table 1

Demographic/clinical characteristic and laboratory findings of the patients and controls

\begin{tabular}{|c|c|c|c|}
\hline Parameters & $\begin{array}{l}\text { Patients }(n=41) \\
\text { Mean } \pm \text { SD }\end{array}$ & $\begin{array}{l}\text { Controls }(n=25) \\
\text { Mean } \pm \text { SD }\end{array}$ & $\mathbf{p}$ \\
\hline $\begin{array}{ll}\text { Sex } & \text { Male n (\%) } \\
& \text { Female n (\%) }\end{array}$ & $\begin{array}{l}16(39.02) \\
25(60.98)\end{array}$ & $\begin{array}{l}9(36.00) \\
16(64.00)\end{array}$ & 0.806 \\
\hline Age (years) & $28.20 \pm 7.87$ & $30.10 \pm 10.48$ & 0.434 \\
\hline Weight (kg) & $56.07 \pm 11.32$ & $72.38 \pm 4.24$ & 0.001 \\
\hline Height (cm) & $158.18 \pm 6.28$ & $172.00 \pm 4.41$ & 0.001 \\
\hline $\mathrm{BMI}\left(\mathrm{kg} / \mathrm{m}^{2}\right)$ & $22.36 \pm 4.07$ & $24.45 \pm 0.74$ & 0.027 \\
\hline SSBP (mmHg) & $96.25 \pm 22.61$ & $97.00 \pm 20.29$ & 0.901 \\
\hline $\mathrm{DBP}(\mathrm{mmHg})$ & $59.50 \pm 14.31$ & $60.00 \pm 14.14$ & 0.899 \\
\hline MAP $(\mathrm{mmHg})$ & $71.75 \pm 16.54$ & $72.33 \pm 15.26$ & 0.895 \\
\hline Hemoglobin (gr/dL) & $8.74 \pm 1.19$ & $13.79 \pm 1.55$ & 0.001 \\
\hline Platelet count (cell/ $\mathrm{mm}^{3}$ ) & $667.83 \pm 310.91$ & $273.60 \pm 40.40$ & 0.001 \\
\hline MPV (fL) & $9.91 \pm 1.11$ & $9.48 \pm 0.70$ & 0.123 \\
\hline WBC count (cell/mm³) & $13.83 \pm 6.62$ & $10.25 \pm 1.80$ & 0.021 \\
\hline Creatinine $(\mathrm{mg} / \mathrm{dL})$ & $0.68 \pm 0.16$ & $0.65 \pm 0.09$ & 0.395 \\
\hline Uric acid (mg/dL) & $4.86 \pm 1.45$ & $4.00 \pm 0.79$ & 0.017 \\
\hline Calcium (mg/dL) & $9.45 \pm 0.59$ & $9.39 \pm 0.50$ & 0.645 \\
\hline Magnesium (mg/dL) & $1.99 \pm 0.19$ & $1.97 \pm 0.18$ & 0.780 \\
\hline Phosphorus (mg/dL) & $4.32 \pm 0.99$ & $4.30 \pm 0.65$ & 0.919 \\
\hline AST (IU/L) & $29.75 \pm 20.00$ & $29.05 \pm 21.20$ & 0.901 \\
\hline ALT (IU/L) & $28.30 \pm 36.91$ & $33.70 \pm 47.16$ & 0.629 \\
\hline Total Bilirubin. (mg/dL) & $2.78 \pm 1.41$ & $0.86 \pm 0.19$ & 0.001 \\
\hline TSH (ulU/mL) & $1.89 \pm 0.99$ & $2.13 \pm 1.08$ & 0.383 \\
\hline Free T4 (ng/mL) & $0.97 \pm 0.13$ & $0.99 \pm 0.13$ & 0.515 \\
\hline Ferritin (ng/mL) & $2370.94 \pm 3652.02$ & $102.95 \pm 25.21$ & 0.008 \\
\hline
\end{tabular}


Student $\mathrm{t}$ test, $\mathrm{p}<0.05$

SD: Standard deviation, BMI: Body mass index, SBP: Systolic blood pressure, DBP: Diastolic blood pressure, MAP: Mean arterial pressure, MPV: Mean platelet volume, WBC: White blood cells, AST: Aspartate aminotransferase, ALT: Alanine aminotransferase, ALP: Alkaline phosphatase, GGT: Gamma-glutamyl transferase, LDH: Lactate dehydrogenase, TSH: Thyroid stimulating hormone

Table 2

Total transfusion count and cardiac T2* scores of the patients $(n=41)$

\begin{tabular}{|lll|}
\hline Parameters & Mean \pm SD & Median (Min-Max) \\
\hline Total transfusion counts (units) & $479.40 \pm 133.81$ & $479.4(306.0-935.0)$ \\
\hline Cardiac T2* MRI (msec) & $30.62 \pm 19.63$ & $30.6(13.0-109.0)$ \\
\hline Parameters & $\mathrm{n}$ & $\%$ \\
\hline Cardiac T2* MRI < 20 (msec) & 12 & 29.27 \\
\hline Cardiac T2* MRI > 20 (msec) & 29 & 70.73 \\
\hline MRI: Magnetic resonance imaging, SD: Standard deviation, \\
\hline
\end{tabular}


Table 3

Electrocardiographic and echocardiographic findings of the patients and controls

\begin{tabular}{|c|c|c|c|c|}
\hline \multicolumn{2}{|c|}{ Parameters } & \multirow{2}{*}{$\begin{array}{l}\text { Patients }(n=41) \\
\text { Mean } \pm \text { SD } \\
76.65 \pm 13.30\end{array}$} & \multirow{2}{*}{$\begin{array}{l}\text { Controls }(n=25) \\
\text { Mean } \pm \text { SD } \\
71.45 \pm 6.19\end{array}$} & \multirow{2}{*}{$\begin{array}{l}\mathbf{p} \\
0.043\end{array}$} \\
\hline ECG & $\mathrm{HR}$ (bpm/min) & & & \\
\hline & P wave (msec) & $97.55 \pm 8.60$ & $91.00 \pm 4.03$ & 0.002 \\
\hline & P wave dispersion (msec) & $59.01 \pm 17.02$ & $54.02 \pm 22.21$ & 0.003 \\
\hline & PR interval (msec) & $143.65 \pm 13.00$ & $130.20 \pm 9.77$ & 0.001 \\
\hline & QRS interval (msec) & $92.05 \pm 13.08$ & $81.50 \pm 7.16$ & 0.001 \\
\hline & QT interval (msec) & $392.20 \pm 34.64$ & $358.20 \pm 28.13$ & 0.001 \\
\hline & QT dispersion (msec) & $30.33 \pm 11.18$ & $14.90 \pm 8.22$ & 0.001 \\
\hline & QTc interval (msec) & $424.23 \pm 15.94$ & $410.75 \pm 13.84$ & 0.001 \\
\hline & QTc dispersion (msec) & $30.05 \pm 11.49$ & $14.90 \pm 8.22$ & 0.001 \\
\hline & JT interval (msec) & $300.90 \pm 39.30$ & $276.50 \pm 24.07$ & 0.014 \\
\hline & JTc interval (msec) & $323.53 \pm 35.82$ & $317.20 \pm 11.29$ & 0.446 \\
\hline & JTc dispersion (msec) & $75.02 \pm 32.01$ & $41.11 \pm 11.90$ & 0.001 \\
\hline & Tp-e interval (msec) & $98.50 \pm 18.75$ & $83.00 \pm 11.15$ & 0.001 \\
\hline & Tp-e dispersion (msec) & $71.07 \pm 10.08$ & $47.03 \pm 21.05$ & 0.005 \\
\hline & Tp-e/QT & $0.25 \pm 0.05$ & $0.23 \pm 0.03$ & 0.045 \\
\hline $\mathrm{ECHO}$ & EF (\%) & $63.00 \pm 4.11$ & $63.35 \pm 2.85$ & 0.734 \\
\hline & FS (\%) & $41.37 \pm 4.12$ & $41.90 \pm 4.19$ & 0.645 \\
\hline & LVEDD (mm) & $47.28 \pm 3.71$ & $46.25 \pm 2.47$ & 0.270 \\
\hline & LVESD (mm) & $29.10 \pm 3.66$ & $28.15 \pm 3.44$ & 0.338 \\
\hline & IVSTd (mm) & $9.20 \pm 1.25$ & $8.57 \pm 0.96$ & 0.052 \\
\hline & LVPWTd (mm) & $8.95 \pm 0.84$ & $8.71 \pm 0.81$ & 0.294 \\
\hline & LVM (g) & $142.93 \pm 31.80$ & $122.44 \pm 16.75$ & 0.004 \\
\hline & LVMI $\left(\mathrm{g} / \mathrm{m}^{2}\right)$ & $76.32 \pm 10.58$ & $69.60 \pm 8.42$ & 0.009 \\
\hline
\end{tabular}




\begin{tabular}{|lll} 
Parameters & Patients $(n=41)$ & Controls $(n=25)$ \\
Mean \pm SD & Mean \pm SD & p
\end{tabular}

Student $\mathrm{t}$ test, $\mathrm{p}<0.05$

SD: Standard deviation, ECG: Electrocardiography, ECHO: Echocardiography, HR: Heart rate, Tp-e: T peak-to-end, EF: Ejection fraction, FS: Shortening fraction, LVEDD: left ventricular end diastolic diameter, LVESD: Left ventricular end systolic diameter, IVST: Intraventricular septum thickness, LVPWT: Left ventricular posterior wall thickness, LVM: Left ventricular mass, LVMI: Left ventricular mass index 
Table 4

Electrocardiographic and echocardiographic findings of patients according to cardiac T2* scores

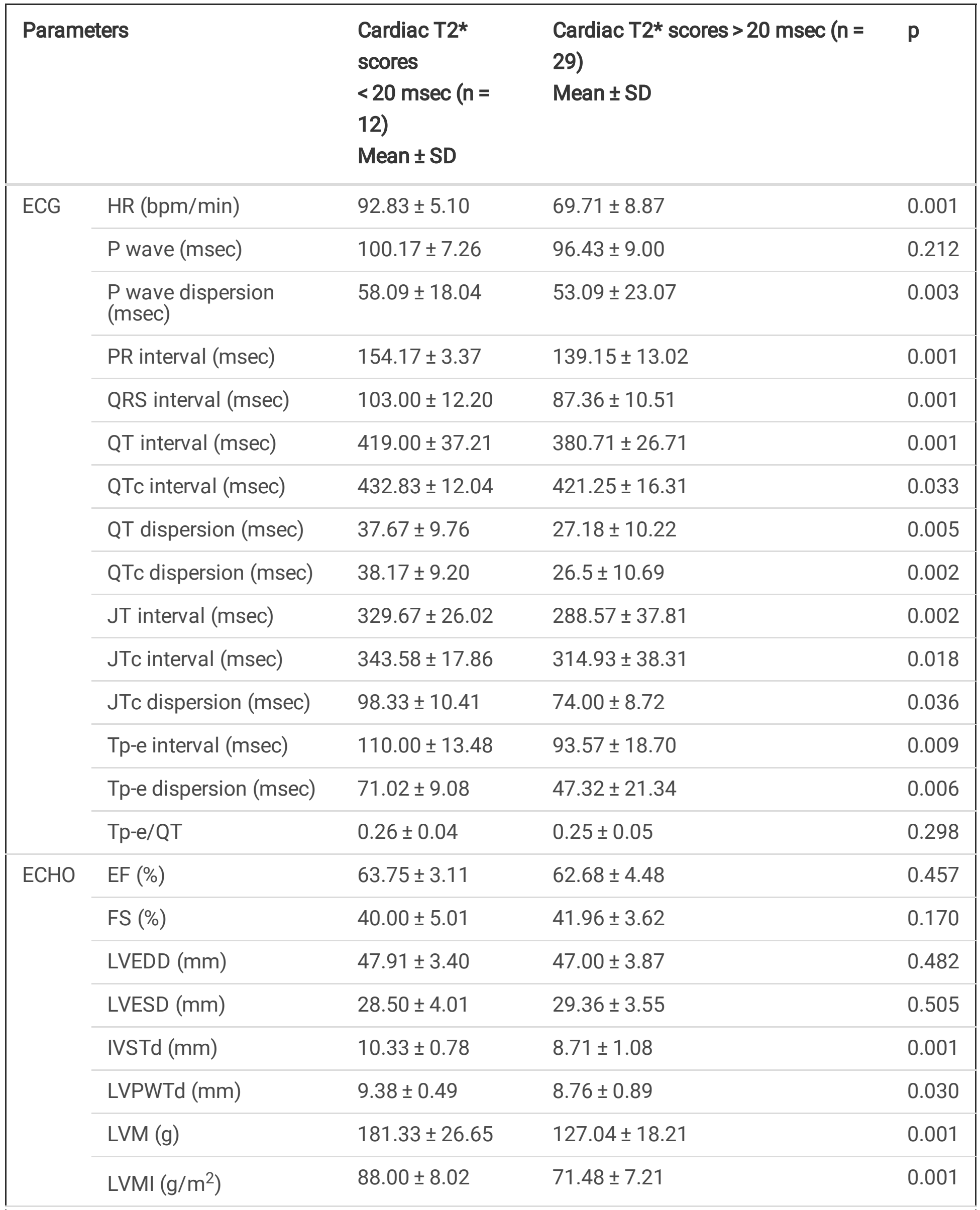




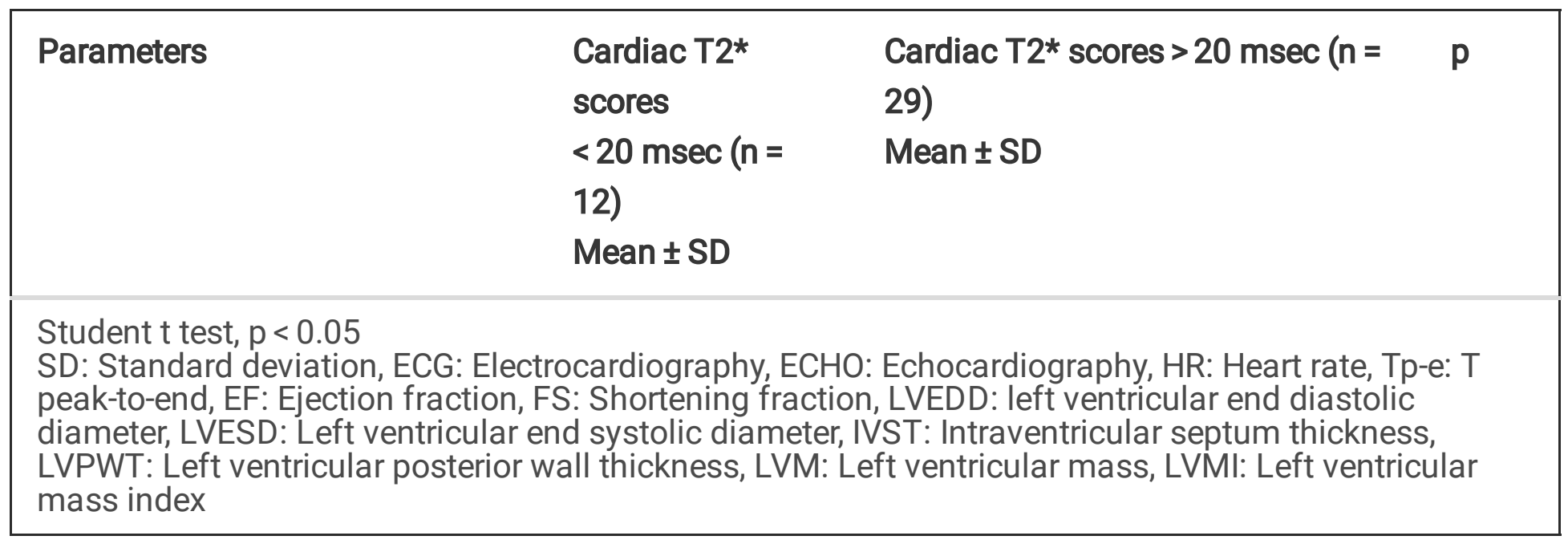


Table 5

The relations of cardiac T2* scores and ferritin levels with ECG and ECHO findings in patients

\begin{tabular}{|c|c|c|c|c|}
\hline \multicolumn{3}{|c|}{ Parameters } & \multirow{2}{*}{$\begin{array}{l}\text { Cardiac T2* (msec) } \\
-0.577\end{array}$} & \multirow{2}{*}{$\begin{array}{l}\text { Ferritin (ng/mL) } \\
0.306\end{array}$} \\
\hline ECG & $\mathrm{HR}$ (bpm/min) & $r$ & & \\
\hline & & $\mathrm{p}$ & 0.001 & 0.055 \\
\hline & \multirow[t]{2}{*}{ P duration (msec) } & $r$ & -0.231 & 0.069 \\
\hline & & $\mathrm{p}$ & 0.151 & 0.673 \\
\hline & \multirow[t]{2}{*}{ PR interval (msec) } & $r$ & -0.565 & 0.304 \\
\hline & & $\mathrm{p}$ & 0.001 & 0.057 \\
\hline & \multirow[t]{2}{*}{ QRS interval (msec) } & $r$ & -0.209 & 0.315 \\
\hline & & $\mathrm{p}$ & 0.197 & 0.048 \\
\hline & \multirow[t]{2}{*}{ QT interval (msec) } & $r$ & -0.221 & 0.201 \\
\hline & & $\mathrm{p}$ & 0.171 & 0.213 \\
\hline & \multirow[t]{2}{*}{ QT-dispersion (msc) } & $r$ & -0.024 & 0.240 \\
\hline & & $\mathrm{p}$ & 0.884 & 0.135 \\
\hline & \multirow[t]{2}{*}{ QTc interval (msec) } & $r$ & -0.295 & 0.268 \\
\hline & & $\mathrm{p}$ & 0.065 & 0.094 \\
\hline & \multirow[t]{2}{*}{ QTc-dispersion (msec) } & $r$ & -0.023 & 0.243 \\
\hline & & $\mathrm{p}$ & 0.889 & 0.131 \\
\hline & \multirow[t]{2}{*}{ Tp-e (msec) } & $r$ & -0.063 & 0.190 \\
\hline & & $\mathrm{p}$ & 0.697 & 0.240 \\
\hline & \multirow[t]{2}{*}{ Tp-e/QT } & $r$ & 0.027 & 0.083 \\
\hline & & $\mathrm{p}$ & 0.868 & 0.610 \\
\hline \multirow[t]{6}{*}{$\mathrm{ECHO}$} & \multirow[t]{2}{*}{ EF (\%) } & $r$ & 0.068 & 0.170 \\
\hline & & $\mathrm{p}$ & 0.677 & 0.296 \\
\hline & \multirow[t]{2}{*}{ LVEDD (mm) } & $r$ & -0.035 & -0.080 \\
\hline & & $\mathrm{p}$ & 0.831 & 0.622 \\
\hline & \multirow[t]{2}{*}{ LVESD (mm) } & $r$ & 0.200 & -0.193 \\
\hline & & $\mathrm{p}$ & 0.217 & 0.233 \\
\hline
\end{tabular}




\begin{tabular}{|c|c|c|c|}
\hline \multicolumn{2}{|l|}{ Parameters } & \multirow{2}{*}{$\begin{array}{l}\text { Cardiac T2* (msec) } \\
-0.068\end{array}$} & \multirow{2}{*}{$\begin{array}{l}\text { Ferritin }(\mathrm{ng} / \mathrm{mL}) \\
0.083\end{array}$} \\
\hline IVST (mm) & $r$ & & \\
\hline & $\mathrm{p}$ & 0.675 & 0.612 \\
\hline \multirow[t]{2}{*}{ LVPWT (mm) } & $r$ & 0.159 & 0.177 \\
\hline & $p$ & 0.326 & 0.276 \\
\hline \multirow[t]{2}{*}{ LVM (g) } & $r$ & -0.407 & 0.258 \\
\hline & $\mathrm{p}$ & 0.008 & 0.104 \\
\hline \multirow[t]{2}{*}{ LVMI $\left(\mathrm{g} / \mathrm{m}^{2}\right)$} & $r$ & -0.368 & 0.171 \\
\hline & $\mathrm{p}$ & 0.018 & 0.284 \\
\hline \multicolumn{4}{|c|}{$\begin{array}{l}\text { r: Correlation Coefficient, } \mathrm{p}<0.05 \\
\text { ECG: Electrocardiography, ECHO: Echocardiography, HR: Heart rate, Tpe: T peak-to-end interval, EF: } \\
\text { Ejection fraction, LVEDD: left ventricular end diastolic diameter, LVESD: Left ventricular end systolic } \\
\text { diameter, IVST: Intraventricular septum thickness, LVPWT: Left ventricular posterior wall thickness, } \\
\text { LVM: Left ventricular mass, LVMI: Left ventricular mass index }\end{array}$} \\
\hline
\end{tabular}

\section{Figures}



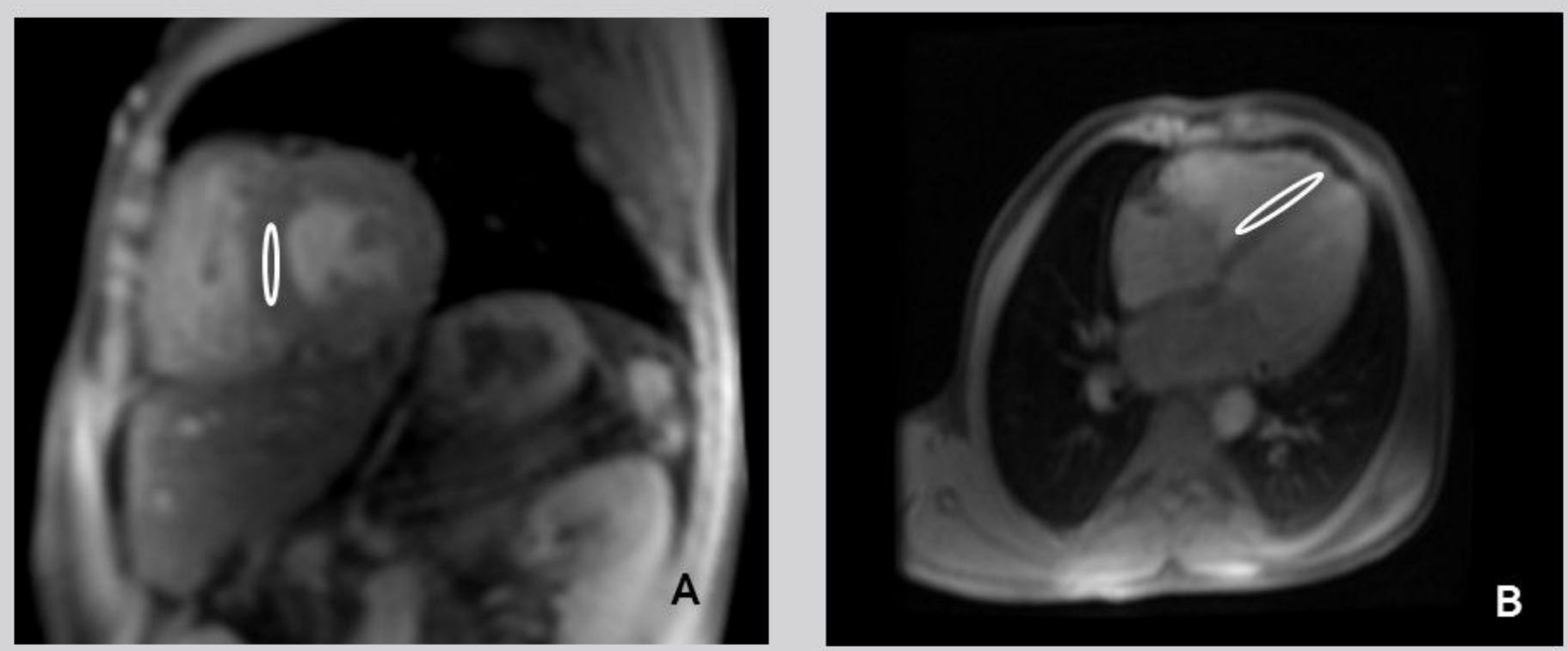

\section{Figure 1}

Short axis view of T2* weighted image. ROI (region of interest) located at interventricular septum. T2* relaxation time shorter than $20 \mathrm{msec}$ in a patient with $\beta$-thalassemia major $(1 \mathrm{~A})$. Four-chamber view of T2* weighted image. ROI (region of interest) located at interventricular septum. T2* relaxation time longer than $20 \mathrm{msec}$ in a patient in control group (1B). 


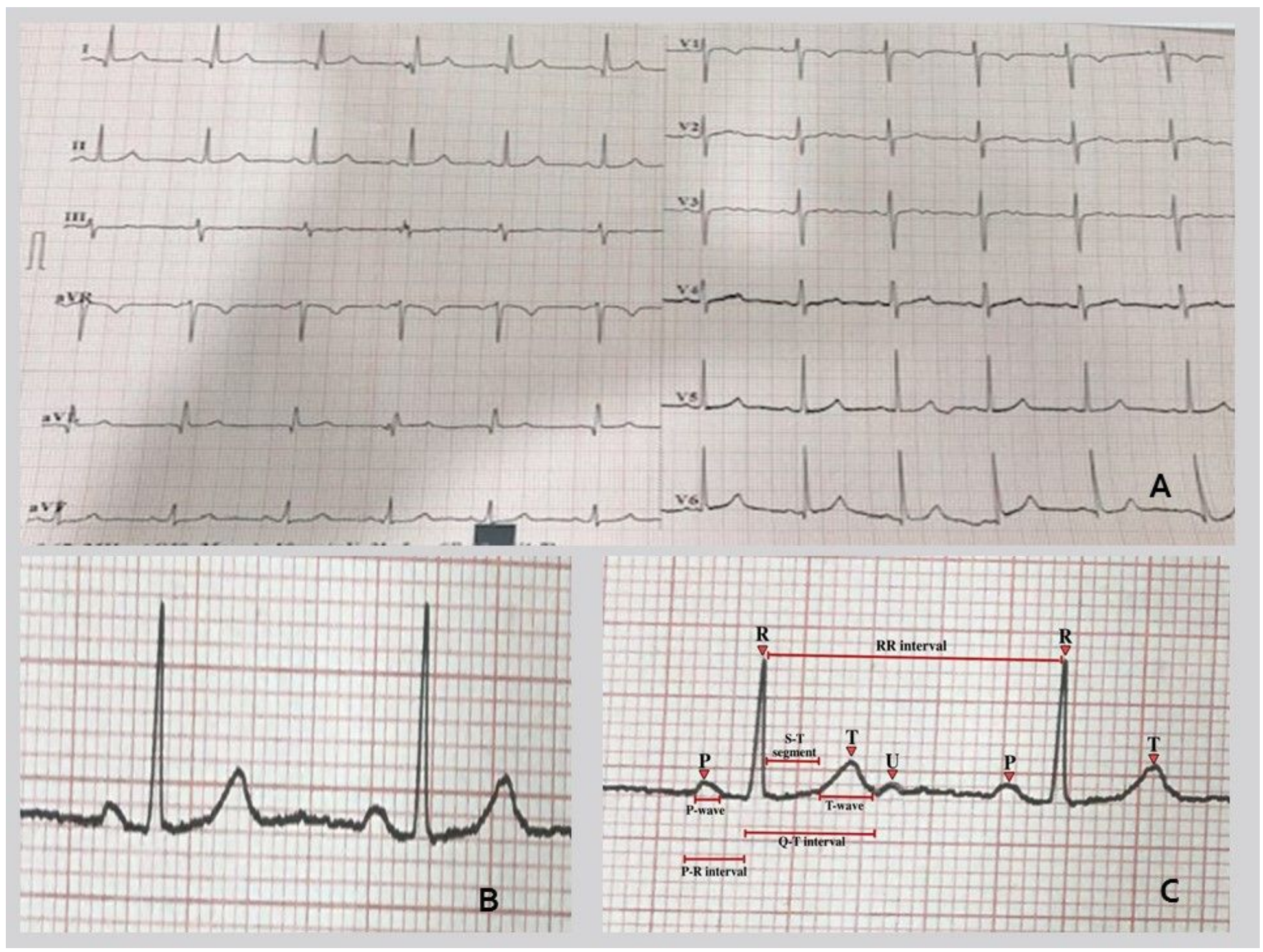

Figure 2

Electrocardiogram (ECG) signal and its main features: peaks $(P, Q, R, S, T, U)$, waves, segments and intervals. IPI, Inter-Pulse Interval of a study participant (2A, 2B, 2C). 


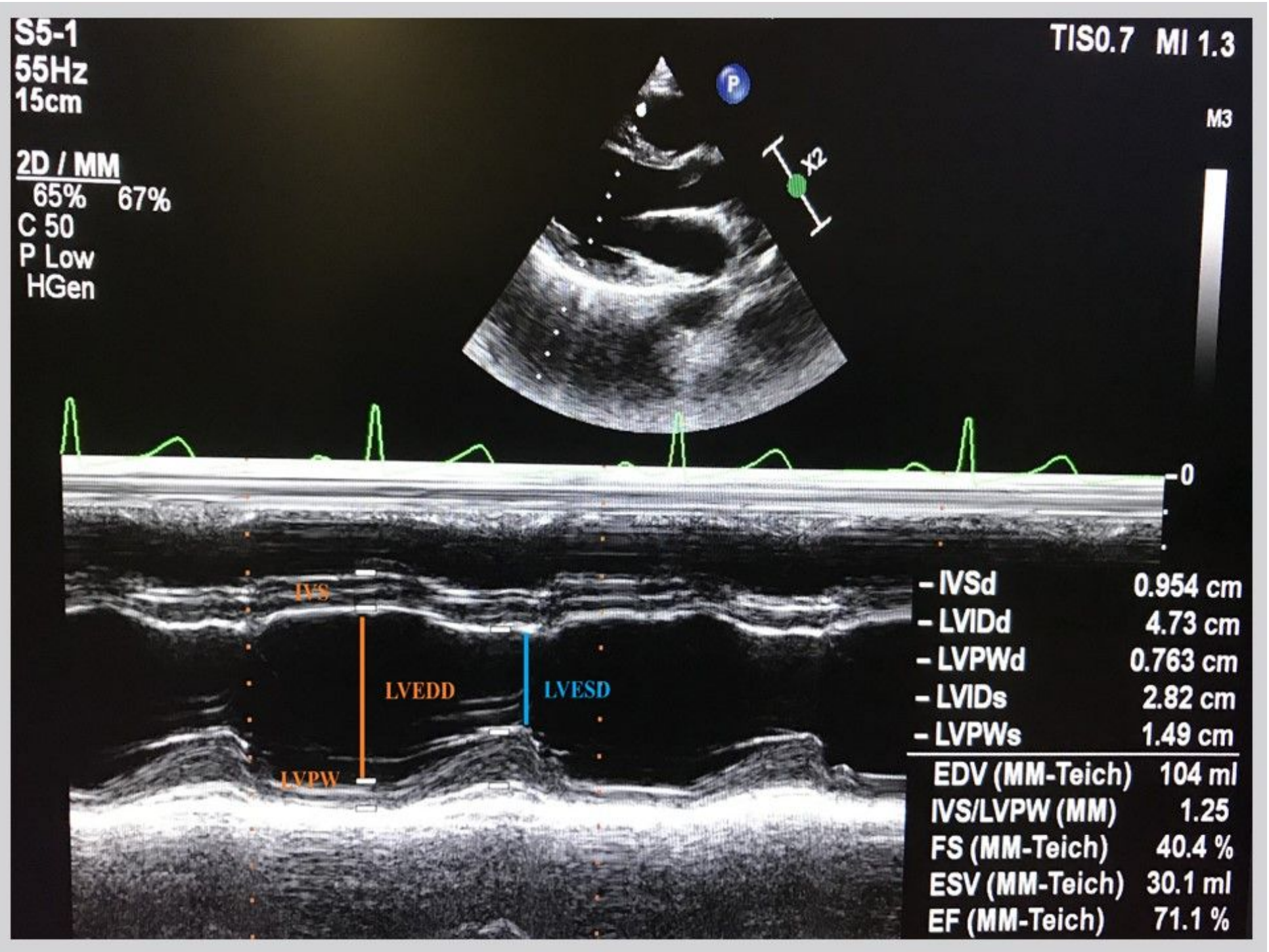

Figure 3

M-mode echocardiography from a parasternal long-axis view showing the left ventricular cavity over the cardiac cycle (see ECG tracing) during systole and diastole. Abbreviations: IVS, interventricular septum; LV, left ventricle; LVEDD, left ventricle end-diastolic dimension; LVESD, left ventricle end-systolic dimension; LVPW, left ventricle posterior wall. 